\title{
Levodopa-responsive depression associated with corticobasal degeneration: a case report
}

\author{
This article was published in the following Dove Press journal: \\ Neuropsychiatric Disease and Treatment \\ 18 April 2017 \\ Number of times this article has been viewed
}

\author{
Natsumi Tarakita' \\ Haruo Nishijima ${ }^{2}$ \\ Norio Yasui-Furukori ${ }^{1}$ \\ 'Department of Neuropsychiatry, \\ Graduate School of Medicine, \\ Hirosaki University, Hirosaki, \\ ${ }^{2}$ Department of Neurology, Aomori \\ Prefectural Central Hospital, \\ Aomori, Japan
}

\begin{abstract}
A 60-year-old female was treated for depression with the antidepressant paroxetine for 13 years. The patient had experienced clumsiness and mild rigidity in the left hand, and had agraphia and mild subjective memory complaints for 3 years prior to admission in our hospital. She experienced exacerbated depression that included worsened depressive mood, lowered motivation, and suicidal ideation without precipitating stressful life events for 2 years prior to admission, and although she had continued taking the antidepressant, these symptoms were not ameliorated by increasing the dose of paroxetine. Following the development of myoclonus and pain in her left arm, we performed magnetic resonance imaging of her head, that revealed diffuse atrophy and right parietal lobe atrophy. The patient was ultimately diagnosed with corticobasal degeneration (CBD). Her left arm myoclonus and depression improved following levodopa administration. Therefore, we concluded that the recurrent depression may have been induced by CBD.
\end{abstract}

Keywords: corticobasal degeneration, depression, cognitive decline

\section{Introduction}

A depressive state is frequently observed in patients with Alzheimer-type dementia and mild cognitive impairment. ${ }^{1-3}$ It is known that depression is a risk factor for the development of Alzheimer's disease. ${ }^{1-3}$ Therefore, depression in middle-aged and older patients may be associated with organic brain changes. Corticobasal degeneration (CBD) is a rare, progressive neurodegenerative disease characterized by progressive asymmetrical rigidity and apraxia. ${ }^{4}$ In addition, CBD can often present with complex cognitive difficulties and neuropsychiatric disturbances. ${ }^{4,5}$ Symptoms of depression, apathy, or agitation can be subtle and are often overlooked as reactions to receiving a new diagnosis of Parkinsonism. ${ }^{4-6}$ Here, we report a case of exacerbated depression with cognitive impairment that was later diagnosed as CBD. After receiving a full description of the study, the patient provided written informed consent for this case to be published.

\section{Case}

A 60-year-old right-handed female with depression who was treated with the antidepressant paroxetine ( $20 \mathrm{mg} /$ day) for 13 years presented to our hospital. Her mental status had remained relatively stable after primary treatment with the prescribed dose of paroxetine. The patient had experienced clumsiness and mild rigidity in her left hand and had agraphia and mild subjective memory complaints for 3 years prior to admission in our hospital. At another hospital, she was diagnosed with Parkinson's disease (PD) and dementia and was administered anti-parkinsonian (levodopa [L-dopa],
Correspondence: Norio Yasui-Furukori Department of Neuropsychiatry, Graduate School of Medicine, Hirosaki University, Hirosaki 036-8562, Japan

$\mathrm{Tel}+8 \mathrm{I} \quad 172395066$

Fax +8I I72 395067

Email yasufuru@hirosaki-u.ac.jp 
$200 \mathrm{mg} /$ day) and anti-dementia (donepezil, $5 \mathrm{mg} /$ day) medications in addition to the antidepressant paroxetine (20 mg/day). She had been admitted to our hospital 2 years prior to the admission in the present case because she presented with exacerbated depression that included worsened depressive mood, lowered motivation, and suicidal ideation without any stressful life events. At admission, cognitive impairment as well as depression was observed, and thus, we performed a head magnetic resonance imaging (MRI), which revealed no cerebral atrophy (Figure 1A), including within the parahippocampal gyrus. Dopamine transporter (DAT) imaging showed no reduction in nigrostriatal DAT accumulation. On the other hand, single-photon emission computed tomography neuroimaging showed a mild decrease in blood flow in the bilateral parietal lobes and posterior cingulate gyrus wedge. The Neurobehavioural Cognitive Status Examination (COGNISTAT) indicated a normal range for naming and judgment, mild impairment of repetition, moderate impairment of similarity, and severe impairment of orientation, attention, comprehension, constructional ability, memory, and calculation. Based on these findings, she was diagnosed with Alzheimer's disease, and the anti-parkinsonian medication L-dopa decarboxylase was stopped and replaced with another anti-dementia drug, memantine, at a dosage of $10 \mathrm{mg} /$ day. Although the dosage of the antidepressant paroxetine was increased from 20 to $30 \mathrm{mg} /$ day, the patient's depressive status was unchanged. After discharge, she developed myoclonus and pain in her left arm, and her depression worsened further. Thus, she was reexamined, and a head MRI revealed diffuse atrophy and right parietal lobe atrophy (Figure 1B). In addition, DAT imaging showed a right-sided decrease in accumulation, and metaiodobenzylguanidine myocardial scintigraphy showed no deficit of accumulation. These brain imaging findings were compatible with CBD. After careful neurological examination, she was finally diagnosed with "probable CBD" according to Armstrong's criteria for CBD. ${ }^{7}$ The patient was prescribed L-dopa (300 mg/day), and both her left arm myoclonus and depression improved. To date, the patient's cognitive function has further decreased, but her mental status has remained stable.

\section{Discussion}

Although the depressive episode that had occurred 13 years prior to admission was not associated with $\mathrm{CBD}$, it is likely that the depressive episode she had experienced 2 years prior to admission was caused by CBD because her depression did not improve with the increased dose of paroxetine and only improved after L-dopa was administered for CBD. Based on her clinical course, the depressive episode probably recurred due to the development of $\mathrm{CBD}$, despite being treated with an antidepressant; therefore, this is the first case of recurrent depression caused by CBD. When depression is associated with neurological symptoms and cognitive dysfunction in elderly patients, CBD should be considered as a differential diagnosis.
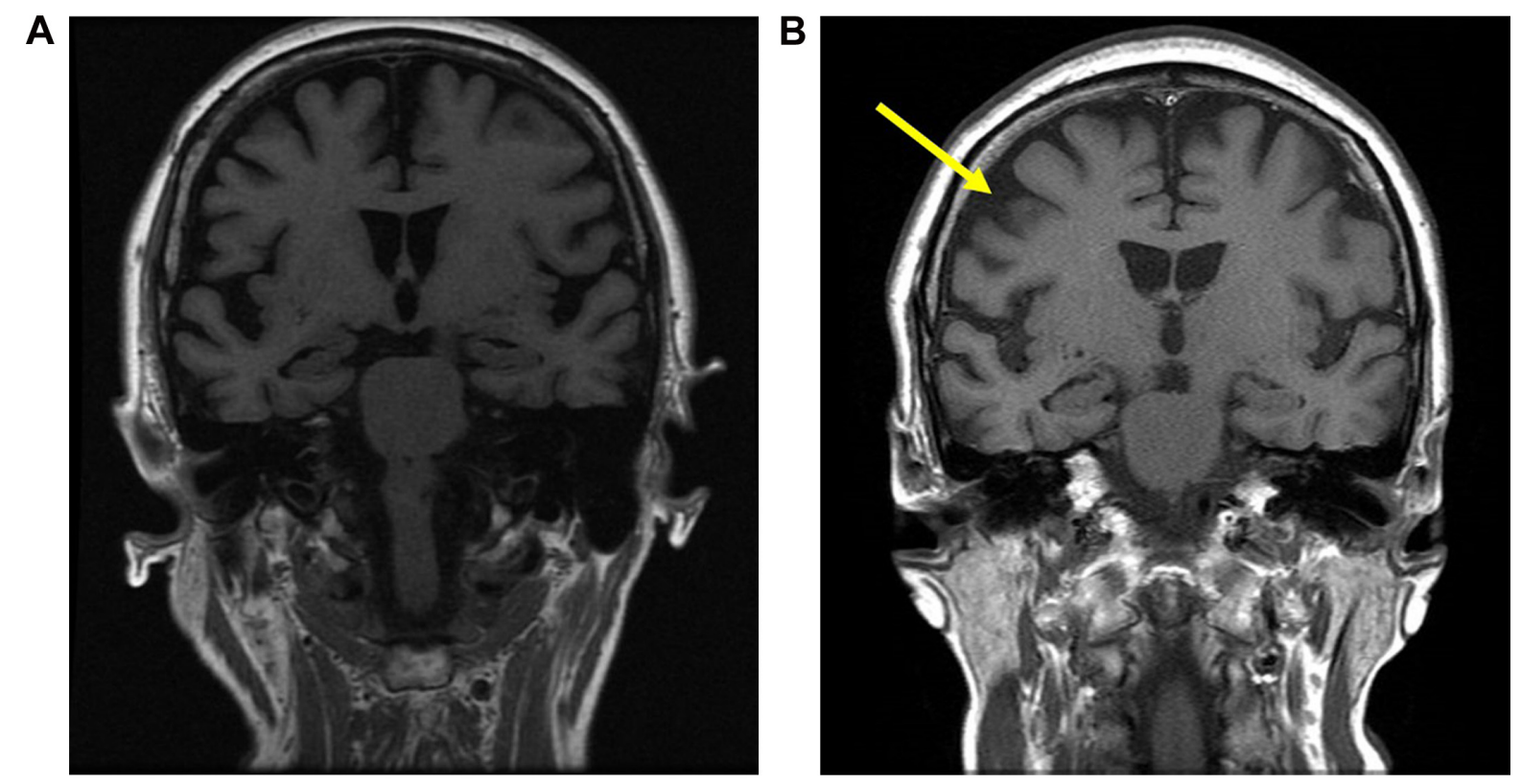

Figure I Brain magnetic resonance imaging revealing (A) no cerebral atrophy 2 years prior to the admission and (B) diffuse atrophy and right parietal lobe atrophy (arrow). 
Psychiatric symptoms in CBD have been shown to include depression, indifference, and irritability. It was reported that the total frequency of apathy, irritability, and disinhibition was $58 \%$, whereas that of depression was $38 \%{ }^{8}$ Eight of 36 autopsied CBD cases (22\%) had psychiatric symptoms, including behavioral dyscontrol (8.3\%), depression $(8.3 \%)$, compulsive behavior $(8.3 \%)$, irritability $(2.8 \%)$, and disinhibition (2.8\%). ${ }^{9}$ Another study showed that social withdrawal was the most common behavioral symptom in autopsy-confirmed CBD cases that fulfilled the diagnostic criteria of behavioral variant frontotemporal degeneration in life..$^{10}$ Disinhibition, stereotypy, and depression were the most frequent psychiatric symptoms, followed by aggression, apathy, self-centered behavior, social withdrawal, and euphoria. ${ }^{11}$

Nonetheless, cognitive and psychiatric disturbances are common even in the early stages of the disease. Executive dysfunction is often measurable in newly diagnosed PD. Although there are no guidelines for the treatment of depression in $\mathrm{CBD}$, there are clear recommendations for the diagnosis of depression in PD. ${ }^{12-14}$ Antidepressant therapies include tricyclic antidepressants and selective serotonin reuptake inhibitors (SSRIs); however, it should be noted that SSRIs could worsen PD symptoms such as rapid eye movement sleep behavior disorder, periodic limb movement, and restless legs syndrome. ${ }^{15,16}$ There is some evidence suggesting the administration of dopamine agonists and monoamine oxidase inhibitors for the treatment of depression in PD. ${ }^{12,15,16}$ Pramipexole and selegiline have been suggested to have some antidepressant effects in addition to their motor effects. ${ }^{15,16}$ If the mood symptoms are only present during the off periods, patients might benefit from drugs targeting the motor symptoms. ${ }^{12}$ However, there is little evidence that L-dopa alone affects mood, ${ }^{16}$ although our case showed some efficacy at least. It can be challenging to distinguish early PD presenting with mild bradykinesia and dopamine-deficiency depressive symptoms from standard SSRI-responsive depression associated with psychomotor retardation, which can be asymmetrical, while mild early PD motor signs can have only subtle asymmetry. DAT imaging can help us distinguish between the two conditions to determine when depression and motor slowing should be treated with an SSRI versus an L-dopa.

The present case suggests that L-dopa may be effective for the treatment of depression associated with CBD, although there is little evidence to date regarding how to address psychiatric symptoms of CBD.

\section{Acknowledgments}

The authors would like to thank Dr Yasushi Sato, Dr Tetsu Tomita, and Prof Kazuhiko Nakamura at Hirosaki University Hospital for their skillful contributions to this case.

\section{Disclosure}

Norio Yasui-Furukori has received grant/research support or honoraria from and has been a lecturer for Asteras, Dainippon, Eli Lilly, GSK, Janssen-Pharma, Meiji, Mochida, MSD, Otsuka, Pfizer, Takeda, and Yoshitomi. The remaining authors have no conflicts of interest to declare in this work.

\section{References}

1. Devanand DP, Sano M, Tang MX, et al. Depressed mood and the incidence of Alzheimer's disease in the elderly living in the community. Arch Gen Psychiatry. 1996;53(2):175-182.

2. Chen P, Ganguli M, Mulsant BH, DeKosky ST. The temporal relationship between depressive symptoms and dementia: a community-based prospective study. Arch Gen Psychiatry. 1999;56(3):261-266.

3. Lyketsos CG, Lopez O, Jones B, Fitzpatrick AL, Breitner J, DeKosky S Prevalence of neuropsychiatric symptoms in dementia and mild cognitive impairment: results from the cardiovascular health study. JAMA. 2002;288(12):1475-1483.

4. Lamb R, Rohrer JD, Lees AJ, Morris HR. Progressive supranuclear palsy and corticobasal degeneration: pathophysiology and treatment options. Curr Treat Options Neurol. 2016;18(9):42.

5. Armstrong RA. Visual signs and symptoms of corticobasal degeneration. Clin Exp Optom. 2016;99(6):498-506.

6. Höglinger GU, Kassubek J, Csoti I, et al. Differentiation of atypical Parkinson syndromes. J Neural Transm (Vienna). Epub 2017 Feb 27.

7. Armstrong MJ, Gronseth G, Anderson DC, et al. Summary of evidencebased guideline: periprocedural management of antithrombotic medications in patients with ischemic cerebrovascular disease: report of the Guideline Development Subcommittee of the American Academy of Neurology. Neurology. 2013;80(22):2065-2069.

8. Wenning GK, Litvan I, Jankovic J, et al. Natural history and survival of 14 patients with corticobasal degeneration confirmed at postmortem examination. J Neurol Neurosurg Psychiatry. 1998;64(2):184-189.

9. Lee SE, Rabinovici GD, Mayo MC, et al. Clinicopathological correlations in corticobasal degeneration. Ann Neurol. 2011;70(2):327-340.

10. Whitwell JL, Jack CR Jr, Parisi JE, et al. Rates of cerebral atrophy differ in different degenerative pathologies. Brain. 2007;130(Pt 4): 1148-1158.

11. Ikeda C, Yokota O, Nagao S, et al. Corticobasal degeneration initially developing motor versus non-motor symptoms: a comparative clinicopathological study. Psychogeriatrics. 2014;14(3):152-164.

12. Grimes D, Gordon J, Snelgrove B, et al; Canadian Neurological Sciences Federation. Canadian guidelines on Parkinson's disease. Can J Neurol Sci. 2012;39(4 Suppl 4):S1-S30.

13. Scottish Intercollegiate Guidelines Network. Diagnosis and Pharmacological Management of Parkinson's Disease: A National Clinical Guideline. Edinburgh: Scottish Intercollegiate Guidelines Network; 2010.

14. Berardelli A, Wenning GK, Antonini A, et al. EFNS/MDS-ES/ENS [corrected] recommendations for the diagnosis of Parkinson's disease. Eur J Neurol. 2013;20(1):16-34.

15. Gelenberg AJ, Freeman MP, Markowitz JC, et al. Practice Guideline for the Treatment of Patients with Major Depressive Disorder. 3rd ed. Arlington, VA: American Psychiatric Association; 2010.

16. Ferreira JJ, Katzenschlager R, Bloem BR, et al. Summary of the recommendations of the EFNS/MDS-ES review on therapeutic management of Parkinson's disease. Eur J Neurol. 2013;20(1):5-15. 


\section{Publish your work in this journal}

Neuropsychiatric Disease and Treatment is an international, peerreviewed journal of clinical therapeutics and pharmacology focusing on concise rapid reporting of clinical or pre-clinical studies on a range of neuropsychiatric and neurological disorders. This journal is indexed on PubMed Central, the 'PsycINFO' database and CAS,

and is the official journal of The International Neuropsychiatric Association (INA). The manuscript management system is completely online and includes a very quick and fair peer-review system, which is all easy to use. Visit http://www.dovepress.com/testimonials.php to read real quotes from published authors.

Submit your manuscript here: http://www.dovepress.com/neuropsychiatric-disease-and-treatment-journal 